\title{
Effect of Filler Loading on Mechanical and Tribological Properties of Wood Apple Shell Reinforced Epoxy Composite
}

\author{
Ojha Shakuntala, ${ }^{1}$ Gujjala Raghavendra, ${ }^{2}$ and Acharya Samir Kumar ${ }^{1}$ \\ ${ }^{1}$ Department of Mechanical Engineering, NIT, Rourkela, Odisha 769008, India \\ ${ }^{2}$ Department of Mechanical Engineering, NIT, Warangal, 506004 Andhra Pradesh, India \\ Correspondence should be addressed to Ojha Shakuntala; shaku30@gmail.com
}

Received 30 May 2013; Revised 20 November 2013; Accepted 11 December 2013; Published 4 February 2014

Academic Editor: Markku Leskela

Copyright (C) 2014 Ojha Shakuntala et al. This is an open access article distributed under the Creative Commons Attribution License, which permits unrestricted use, distribution, and reproduction in any medium, provided the original work is properly cited.

\begin{abstract}
During the last century, natural fibers and particulates are used as reinforcement in polymer composite that has been continuously growing in the composite industry. This polymer matrix composite has wide range of applications in hostile environment where they are exposed to external attacks such as solid particle erosion. Also, the mechanical properties of different polymer composites show the best alternate to replace the metal material. In the present investigation, an attempt has been made to improve the mechanical and tribological behaviour of polymer matrix composite using wood apple shell particles as a filler material in polymer matrix. Also the temperature variation of the dynamic-mechanical parameters of epoxy matrix composites incorporated with $5,10,15$, and $20 \mathrm{wt} \%$ of wood apple shell particles was investigated by DMA test. It is clearly observed that the incorporation of wood apple shell particles tends to increase the tensile strength, flexural strength, erosive wear resistance, and viscoelastic stiffness of the polymer composite. To validate the results, SEM of the polymer matrix composite has been studied.
\end{abstract}

\section{Introduction}

Bio and industrial waste are finding increased application under different conditions in which they may be utilised as value-added products. Many scientists are looking for new and alternative materials due to the paucity of metals. Their survey reveals that natural waste products have the potential to replace the conventional materials. These natural waste products include banana, bamboo, coconut shell, oil palm shell, jute, rice husk, and henequen, which are attractive due to their low cost, easy fabrication, high strength to weight ratio, better thermal and insulating properties, renewable, completely or partially recyclable, and biodegradable [1-4]. Due to the reinforcement of natural filler materials in the matrix composite, increase the modulus, decrease the ductility of the matrix, and also reduce the cost of the composites. Natural filler polymer composites offers better application in the fields of mechanical, tribological and industial when compared to synthetic material composites $[5,6]$.

Many investigations have been made by the researchers on the potential of the natural fillers as reinforcements for composites. Bujang et al. [7] have determined the mechanical properties and dynamic characteristics of a proposed combined polymer composite which consist of a polyester matrix and coconut fibres (also known as coir fibres). Abdul Khalil et al. [8] studied the behaviour of the epoxy composite when filled with biobased fillers like bamboo stems, coconut shells, and oil palm fiber bunch. Fu et al. [9] have studied the flexural properties of misaligned short fiber reinforced polymers by taking into account the effects of fiber length and fiber orientation. Tensile and flexural behaviour of pineapple leaf fiber-polypropylene composites as a function of volume fraction were investigated. The tensile modulus and tensile strength of the composites were found to be increasing with fiber content in accordance with the rule of mixtures [10]. Mwaikambo and Bisanda [11] reported that, for polyester/cotton fabric composites, the tensile strength of the composites decreased with increasing content of the cotton fabric, possibly because the void content increases with increasing fabric volume fraction [12]. Margem et al. conducted experiments to find out the mechanical strength of ramie fiber and also investigated the temperature variation 
resistance of composites along with epoxy in DMA analysis. Gang Sui [14] fabricated an epoxy composite using Cancun natural hydrophobic sand particle as filler material and found through dynamic mechanical analysis (DMA) that the storage modulus and glass transition temperature of the sand particles/epoxy composites were increased compared to the pristine epoxy. There are some possibilities where the composite may encounter impacts of materials like sand and slurry of solid particles so consequently the material may failed due to erosion wear [15]. The erosion wear of reinforced polymer composite is usually higher than unreinforced polymer matrix [16]. Rajesh et al. [17] selected a series of polyamides for investigating the effects of chemical structure and hence, mechanical properties on erosive wear behaviour by impinging silica sand particles at various angles and doses. The results indicated that the influence of velocity impact on erosion rate was more dramatic at an oblique impact angle $\left(30^{\circ}\right)$ than at normal impact angle $\left(90^{\circ}\right)$.

Numerous research works are carried out on various filler materials that can give good dispersion and interfacial adhesion between the filler and polymer matrices. In this work, we fabricated an epoxy composite using a new natural filler material, that is, wood apple shell particulate, because particulate reinforced polymer composites are very attractive due to the ease of manufacturing and mould ability. Anusha [18] used wood apple shell particulates as an absorbent for the removal of iron from waste water. Ahmad and Kumar [19] also studied the adsorptive removal of Congo red dye from aqueous solution using bael shell carbon.

Wood apple (Aegle marmelos) that belongs to family Rutaceae is a highly reputed medicinal tree commonly known as bael, shown in Figure 1. It is an indigenous fruit of India. It is grown throughout Southeast Asian countries like India, Sri Lanka, Pakistan, Bangladesh, Burma, and Thailand. The peel of the fruit which is very hard shell and green to brown in colour depends on ripening stage. Wood apple shell mainly consists of carbohydrate component such as cellulose, hemicellulose, and lignin.

The main aim of this research was to investigate the influence of wood apple shell particles on mechanical and tribological properties of epoxy composites and also study the temperature variation of the dynamic-mechanical parameters such as storage modulus and loss modulus of epoxy matrix composites incorporated with wood apple shell particles by DMA tests.

\section{Materials and Methods}

2.1. Particulate Preparation. The wood apple shell (WAS) used in this study is washed several times with distilled water to remove the impurities and waste. The shell material was dried at $110^{\circ} \mathrm{C}$ for $48 \mathrm{~h}$ in an oven to remove excess water content and moisture. After drying, the raw materials were crushed into small pieces with the help of a crusher. After crushing the small pieces of shell materials, and finally converted into fine granular size particles by ball mill for $48 \mathrm{~h}$. The particle size used in this experiment was $212-1 \mu \mathrm{m}$. The SEM of the particle size is shown in Figure 2.

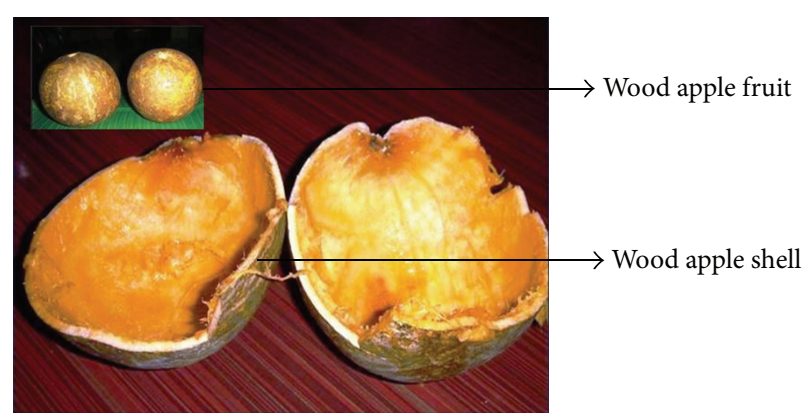

FIGURE 1: Wood apple shell.

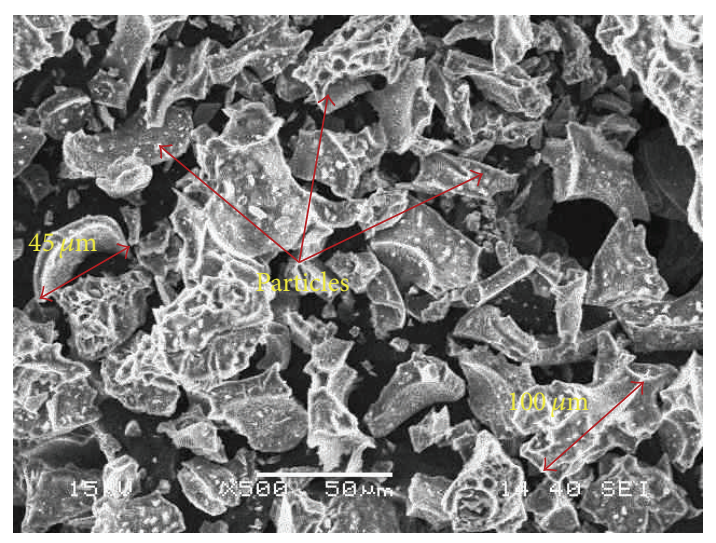

Figure 2: Wood apple shell particles.

TABle 1: Proximate analysis (\% by mass) of wood apple shell particles.

\begin{tabular}{lc}
\hline Sample & Wood apple shell \\
\hline Fixed carbon & 19.21 \\
Moisture & 6.6 \\
Ash & 0.85 \\
Volatile & 73.34 \\
\hline
\end{tabular}

2.2. Raw Material Analysis. Proximate analysis is one of the most important characterization methods to analyse the biofiller. It consists of determining moisture, ash, volatile matter, and fixed carbon contents of the biomass. The proximate analysis of wood apple shell particles is presented in Table 1.

The ultimate analysis of a sample determines the elemental compositions (carbon $(\mathrm{C})$, hydrogen $(\mathrm{H})$, nitrogen $(\mathrm{N})$, and sulphur (S) contents) of the sample which is presented in Table 2. It is based on the principle of Dumas method which involves the complete and instantaneous oxidation of the sample by flash combustion. An ultimate analyzer (CHN932, Leco) was used for analyzing the chemical composition of wood apple shell particulates. The chemical composition of wood apple shell particles is presented in Table 3.

2.3. Composite Fabrication. A wooden mold of $150 \times 60 \times$ $5 \mathrm{~mm}^{3}$ is used for manufacturing the composite. A mold release spray was applied at the inner surface of the mold for quick and easy release of the composite. The wood apple 
TABLE 2: Ultimate analysis of wood apple shell particles.

\begin{tabular}{lc}
\hline Sample & Wood apple shell \\
\hline C & 52.59 \\
H & 6.355 \\
N & 0.34 \\
S & 0.00 \\
\hline
\end{tabular}

TABLE 3: Chemical composition of wood apple shell particles.

\begin{tabular}{lc}
\hline Sample & Wood apple shell \\
\hline Cellulose & 39.54 \\
Hemicellulose & 26.06 \\
Lignin & 29.86 \\
Ash & 0.9 \\
\hline
\end{tabular}

shell particulate composites were prepared by hand layup technique. Five different types of composites are prepared with varying weight fractions $(0,5,10,15$, and $20 \mathrm{wt} \%)$ of particles and epoxy.

Epoxy LY 556 (bisphenol-A-diglycidyl-ether) is used in the present studies, chemically belonging to the "epoxide" family, is used as the matrix material. The epoxy resin and the hardener are supplied by Ciba Geigy India Ltd.

Ten percentage of hardener HY951 is mixed in the resin earlier to reinforcement. A proper stirring is done with mechanical stirrer for uniform mixing of particulates. Then the mixture of particulate and epoxy along with hardener was poured into the mould and after few minutes $30 \mathrm{~kg}$ of load is applied on the composite for $24 \mathrm{~h}$ for better increase of strength. Due to applying of load some amount of the polymer may squeezed out from the mould for this care has taken to ensure no polymer may squeeze out from mould. When the composite was hardened it was removed from the mould and cut with a diamond cutter according to ASTM standard for different tests.

2.4. Density and Void Fraction. In terms of weight fraction the theoretical density of the composite materials can be calculated using Agarwal and Broutman [17] equation:

$$
\rho_{\mathrm{ct}}=\frac{1}{\left(W_{f} / \rho_{f}\right)+\left(W_{m} / \rho_{m}\right)},
$$

where " $W$ " and " $\rho$ " represent the weight fraction and density, respectively. The suffixes " $f$ ", " $m$ ", and "ct" stand for the fiber, matrix, and theoretical density of composite materials, respectively. According to present study the composite consists of matrix and particulate filler. Hence the modified form of above expression for the density of the composite can be written as

$$
\rho_{\mathrm{ct}}=\frac{1}{\left(W_{m} / \rho_{m}\right)+\left(W_{p} / \rho_{p}\right)},
$$

where the suffix " $p$ " represents the particulate filler materials.
TABle 4: Density and void contain of wood apple shell.

\begin{tabular}{lccc}
\hline $\begin{array}{l}\text { \% of } \\
\text { filler }\end{array}$ & $\begin{array}{c}\text { Actual density } \\
(\mathrm{g} / \mathrm{cc})\end{array}$ & $\begin{array}{c}\text { Theoretical density } \\
(\mathrm{g} / \mathrm{cc})\end{array}$ & $\begin{array}{c}\text { Volume fraction } \\
\text { of voids }(\%)\end{array}$ \\
\hline Epoxy & 1.1800 & 1.2 & 1.66 \\
5 & 1.1799 & 1.193 & 1.06 \\
10 & 1.1755 & 1.185 & 0.83 \\
15 & 1.1725 & 1.178 & 0.48 \\
20 & 1.18 & 1.171 & 0.76 \\
\hline
\end{tabular}

However the actual density of the composite materials in terms of weight fraction is determined experimentally by (3) and (4) using Archimedes' principle:

$$
S_{\mathrm{ct}}=\frac{W_{0}}{\left(W_{0}\right)+\left(W_{a}-W_{b}\right)}
$$

where "S" indicates the specific gravity of the composite and " $W_{0}$ ", " $W_{a}$ ", and " $W_{b}$ " represent the weight of the sample, weight of the bottle + kerosene, and weight of the bottle + kerosene + sample. Hence the actual density of the composite materials can be obtained using the following equation (4). The actual and the theoretical density are given in Table 4.

Consider

$$
\rho_{\mathrm{ca}}=S_{\mathrm{ct}} \times \rho_{k} .
$$

The volume fraction of voids $\left(V_{v}\right)$ in the composite is calculated by

$$
V_{v}=\frac{\rho_{\mathrm{ct}}-\rho_{\mathrm{ca}}}{\rho_{\mathrm{ct}}},
$$

where " $\rho$ " represents the density of the composite. The suffixes "ct" and "ca" stand for the theoretical and actual density of the composite materials. The volume fraction of voids present in the composite is shown in Table 4.

2.5. Tensile Test. The tensile tests are conducted according to the ASTM D638-99 standard. The dumbbell-shaped samples for tensile test are cut with a circular diamond blade. The tensile specimen is placed in the testing machine and a care has to be taken taken when aligning the longitudinal axis of the specimen. Servohydraulic controlled INSTRON H10KS dynamic material testing system is used for tensile testing.

2.6. Flexural Test. In order to determine the flexural properties of the composites a three-point bending test is carried out according to D790-99 standard. Bending property of wood composite is very necessary for structural application to avoid failure. The rectangular samples for bend test are cut by using diamond cutter and followed by grinding. The span of $70 \mathrm{~mm}$ and a crosshead speed used for the flexural tests (three-point bending) is $5 \mathrm{~mm} / \mathrm{min}$. The machine is designed to elongate the specimen at a constant rate and to continuously and simultaneously measure the instantaneous applied load and 
the resulting elongations using an extensometer. The flexural strength was calculated by the formula:

$$
\sigma_{\max }=\frac{\left(3 P_{\max } L\right)}{b t^{2}},
$$

where " $P_{\max }$ " is the maximum load at failure $(\mathrm{N})$, " $L$ " is the span $(\mathrm{mm})$, and " $b$ " and " $t$ " are the width and thickness of the specimen $(\mathrm{mm})$, respectively.

2.7. Interlaminar Shear Strength (ILSS). The value of interlaminar shear strength (ILSS) was found out by using short beam shear test method as per the ASTM standard D 234484 . Load is applied at the rate of $1.3 \mathrm{~mm} / \mathrm{min}$. The force applied at the time of failure was recorded and the stresses were determined using

$$
\mathrm{SH}=\frac{\left(0.75 P_{B}\right)}{b h},
$$

where SH is interlaminar shear strength $\left(\mathrm{N} / \mathrm{mm}^{2}\right)$, " $P_{B}$ " is the breaking load (N), and " $b$ " and " $h$ " are width and depth of the specimen $(\mathrm{mm})$. Span to depth ratio of $5: 1$ was selected for the test. A minimum of five samples of each type were tested and the average ILSS values were determined.

2.8. Dynamic Mechanical Test. Dynamic mechanical analysis (DMA) is a powerful technique to investigate thermal and mechanical properties of polymers. The specimens generally deform sinusoidally in response to an applied oscillating force. The resultant strain in specimen due to the sinusoidal load depends upon both elastic and viscous behavior of the specimen. In this study, the storage modulus $\left(E^{\prime}\right)$ and the loss modulus $\left(E^{\prime \prime}\right)$ of neat epoxy and composites were determined by DMA. The storage modulus (or elastic modulus) reflects the elastic modulus of the composites which measures the recoverable strain energy in a deformed specimen, and the loss modulus (or viscous modulus) is related to the energy lost due to energy dissipation as heat. DMA was run in the dual cantilever bending mode. The temperature interval was from room temperature, about $25^{\circ} \mathrm{C}$, to $200^{\circ} \mathrm{C}$ with a heating rate of $1.5^{\circ} \mathrm{C} / \mathrm{min}$ and using a frequency of $1 \mathrm{~Hz}$. Dynamic mechanical analysis (DMA) was performed to initially investigate if the addition of the wood apple shell particles with epoxy will improve the mechanical properties.

2.9. Erosion Testing. The erosion test was conducted on erosion wear test rig according to the ASTM G76-95 standard test method. In the erosion test apparatus, dry and compressed air is used to accelerate the abrasive particles to strike the test specimen and pressure changes at the nozzle are adjusted with a pressure regulator and controlled with a manometer. Angular silica sand abrasive particles with the average size range $150-250 \mu \mathrm{m}$ of irregular shape are used as erodent agents. By double disc method the impact velocity of the particles was found to be $48 \mathrm{~m} / \mathrm{s}$. The parameters for the erosion experiment are given in Table 5. The weight loss is recorded for subsequent calculation of erosion rate.
TABLE 5: Experimental condition for the erosion test.

\begin{tabular}{lc}
\hline \multicolumn{2}{c}{ Test parameters } \\
\hline Erodent & Silica sand \\
Erodent size $(\mu \mathrm{m})$ & $200 \pm 50$ \\
Erodent shape & Angular \\
Hardness of silica particles $(\mathrm{HV})$ & $1420 \pm 50$ \\
Impingement angle $\left(\alpha^{0}\right)$ & $30,45,60$ and 90 \\
Impact velocity $(\mathrm{m} / \mathrm{s})$ & 48 \\
Erodent feed rate $(\mathrm{gm} / \mathrm{min})$ & $2.107 \pm 0.02$ \\
Test temperature & $\mathrm{RT}$ \\
Nozzle to sample distance $(\mathrm{mm})$ & 10 \\
\hline
\end{tabular}

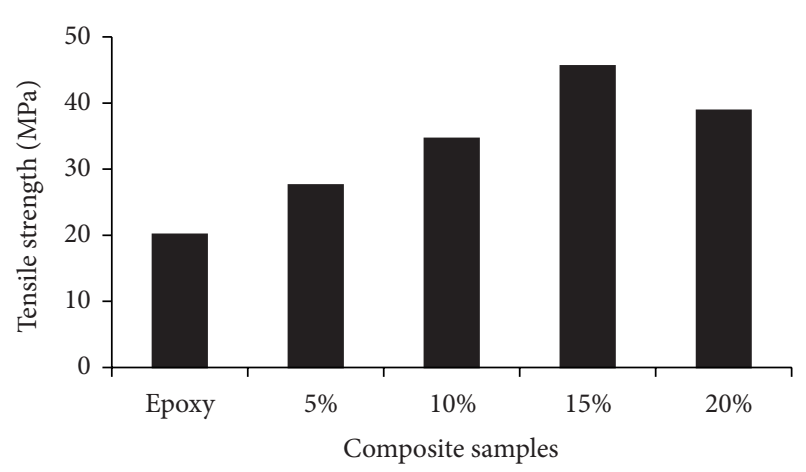

Figure 3: Effect of tensile strength of composite.

\section{Results and Discussion}

3.1. Density and Void Fraction. Density of the composites decreases with increasing the filler content as compared to polymer; this is due to the lighter density of filler material $(1.068 \mathrm{~g} / \mathrm{cc})$. The void content decreases with increasing filler content up to $15 \mathrm{wt} \%$ this may be due to addition of less hydrophilic filler material. Beyond $15 \mathrm{wt} \%$ the void content slightly increases; this is due to imbalance of filler and matrix weight percentage shown in Table 4 .

3.2. Mechanical Properties. The mechanical properties of a composite depend on the nature of the filler, resin, resinfiller adhesion, and cross-linking agents and not the least on the method of the processing. Therefore, any improvement in the property is evaluated as compared to that of the polymer matrix undergone the same processing. The fillers are impregnated by the liquid resin usually at room temperature and then treated with some cross-linking agent for hardening. Usually with an increase in the filler content in the composition, the tensile and flexural property gradually improves. Beyond certain limit of the filler content, however, depending on the method of processing, the adhesion between the resin and the filler decreases resulting in the decrease in the strength of final products [20].

3.2.1. Tensile Properties. Figure 3 shows the effect of filler loading on the tensile strength of wood apple shell particulate composite. It was observed that tensile strength increased 
TABLE 6: Mechanical properties of some epoxy polymer composites.

\begin{tabular}{lccccc}
\hline Resin & Filler (particles) & Corresponding filler content (wt\%) & Tensile strength (MPa) & Flexural strength (MPa) & Reference \\
\hline Epoxy & Wood apple shell & $\mathbf{1 5}$ & $\mathbf{4 5 . 6}$ & $\mathbf{7 8 . 1 9}$ & \\
Epoxy & Coconut shell & 20 & 30.60 & 63.45 & 62.35 \\
Epoxy & Orange peel & 20 & 25.85 & 52.47 & {$[24]$} \\
Epoxy & Ipomoea carnea & 30 & 23.75 & {$[25]$} \\
Epoxy & Pineapple-leaf & 30 & - & {$[26]$} & 80.2 \\
\hline
\end{tabular}

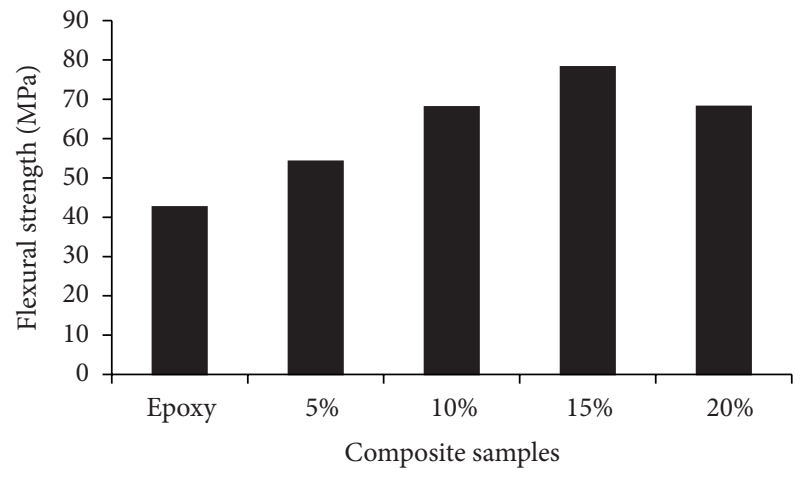

FIGURE 4: Effect of flexural strength of composite.

with increasing filler loading up to $15 \mathrm{wt} \%$; after that the strength of the composite slightly decreased at $20 \mathrm{wt} \%$ filler loading. Joseph et al. have found the same trend [21] in their research. It is generally agreed that, at high filler loading, it is more difficult for the polymer to penetrate the decreasing spaces between the fillers, leading to poor wetting and hence, a reduction in the stress transfer efficiency across the fillerresin interface.

3.2.2. Flexural Properties. Figure 4 shows the flexural strength of wood apple shell particulate composite at different filler loading. The result shows the same trend as with the tensile properties. Flexural strength of wood apple shellepoxy composite is increased from $54.2 \mathrm{MPa}$ to $78.19 \mathrm{MPa}$ and then decreased from $78.19 \mathrm{MPa}$ to $68.16 \mathrm{MPa}$. Similar results were also observed by Ismail et al. [22] and Yao and $\mathrm{Li}$ [23]; this decrease is attributed to the inability of the filler to support stresses transferred from the polymer matrix and poor interfacial bonding generates partially spaces between filler and matrix materials which generates a weak structure.

Epoxy resin has excellent adhesion to a large number of materials and could be further strengthened with the addition of fiber or particulates. The improved strength of the epoxy due to filler addition and a comparison of optimum results obtained in many natural fillers with wood apple shell are shown in Table 6. From the results it is observed that the wood apple shell reinforced composite gives best results at $15 \mathrm{wt} \%$ filler in both tensile and flexural cases when compared with the other filler loading.

3.2.3. Interlaminar Shear Strength (ILSS). Generally ILSS increases with the reduction of void fraction. From the ILSS

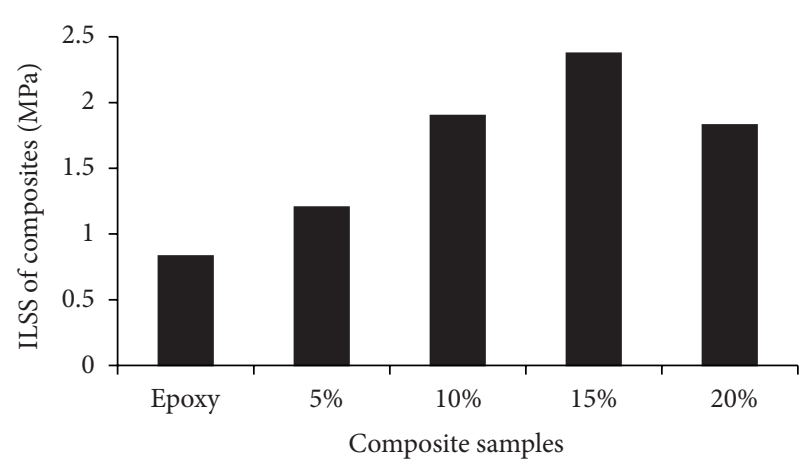

FIGURE 5: Effect of ILSS of composite.

results shown in Figure 5, it is observed that increasing the filler content leads to the increase of the ILSS of the composites, which can be related to the effect of increasing the degree of adhesion at interfaces among the filler and matrix materials. The factors that caused the improvements in ILSS properties are the load transfer capability between the matrix and filler materials and strong interfacial bonding between filler and matrix [28]. But at $20 \mathrm{wt} \%$ ILSS slightly decreases due to increasing the void content or crack formation at the interface of composite.

3.2.4. Dynamic Mechanical Analysis. Figure 6 compares the variation of the storage modulus, $E^{\prime}$, for the different wood apple shell particles composites investigated, as a function of the temperature. The curves in this figure revealed that the incorporation of wood apple shell particles sensibly increases the value of $E^{\prime}$. In fact, at $25^{\circ} \mathrm{C}, E^{\prime}$ for pure epoxy is around $1.122 \mathrm{GPa}$ and for $15 \%$ filler composite is around $2.447 \mathrm{GPa}$. This means that the wood apple shell particles increase the epoxy matrix capacity to support mechanical constraints with recoverable viscoelastic deformation. In particular the composite stiffness is substantially increased with shell particles incorporation.

Figure 7 depicts the variation of the loss modulus, $E^{\prime \prime}$, for the different composites investigated, as a function of the temperature. All $E^{\prime \prime}$ curves in this figure show broad peaks with distinct amplitude and temperatures positions, as compared to the pure epoxy peak. These can be associated with the " $\alpha$ " peak and suggest a more complex structural relaxation behavior by the composites. According to Mohanty et al. [29], this relaxation is attributed to the chain mobility of the polymeric matrix. It is noticed from Figure 8 that all composite peaks are displaced to lower temperatures in 


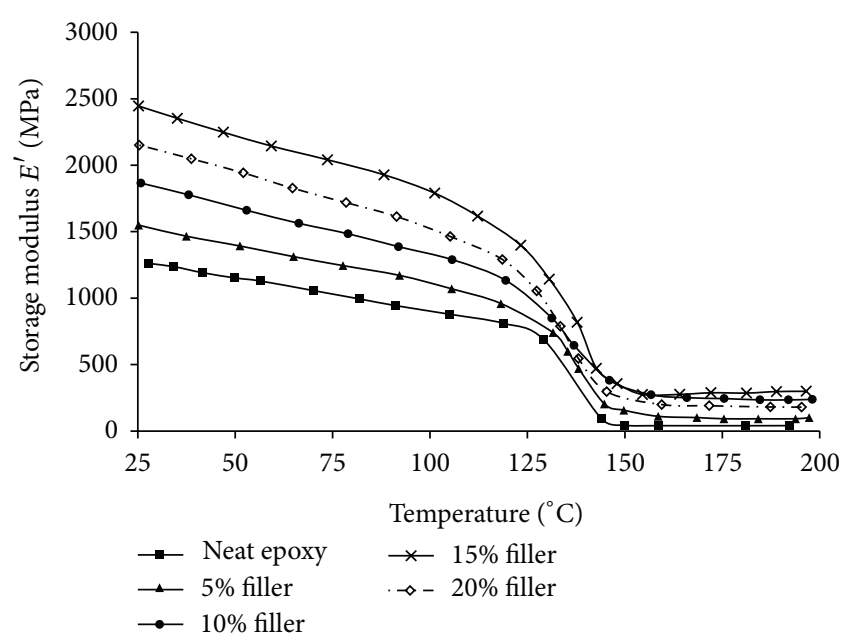

FIGURE 6: Variation of the storage modulus with the temperature for the pure epoxy and the composites reinforced with different volume fractions of wood apple shell particles.

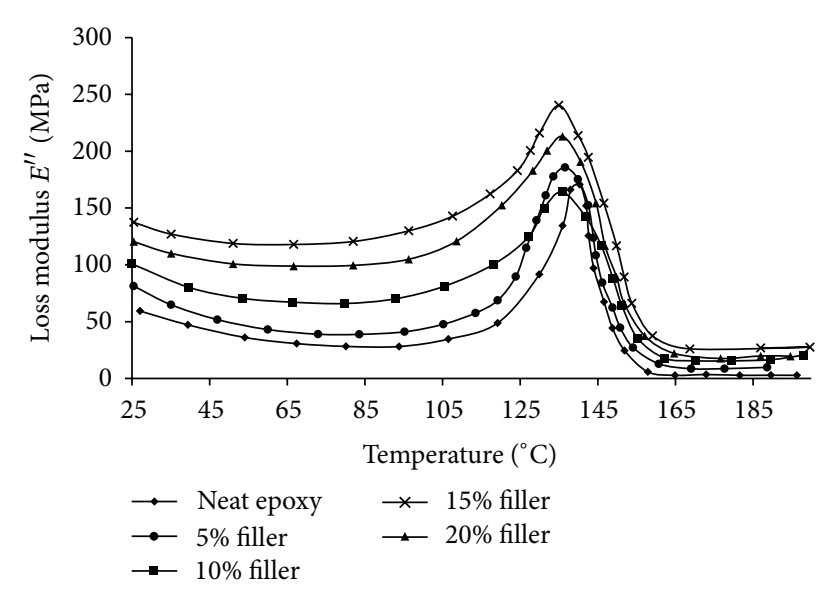

FIGURE 7: Variation of the loss modulus with the temperature for the pure epoxy and the composites reinforced with different volume fractions of wood apple shell particles.

comparison to the pure epoxy peaks. This is possible due to an increase in the flexibility of the epoxy chains caused by the incorporation of wood apple shell particles. On the contrary, the peaks of $E^{\prime \prime}$ for the polymer composites [30] are displaced to higher temperatures indicating a reduction in the chain flexibility.

3.2.5. Erosion Wear Properties. Figure 8 shows the influence of impingement angle on erosive wear of wood apple shell particulate epoxy composite. It is clearly observed from the figure the impingement angles significantly influencing erosion rate. The maximum erosion is occurring in between 40 and $60^{\circ}$ impingement angle of all composite samples irrespective of filler loading. Increase in impingement angle 30 to $45^{\circ}$ under similar operating conditions shows slight increase in erosion rate. It can be seen that the weight loss was maximum at $45^{\circ}$ impingement angle for all composites. So

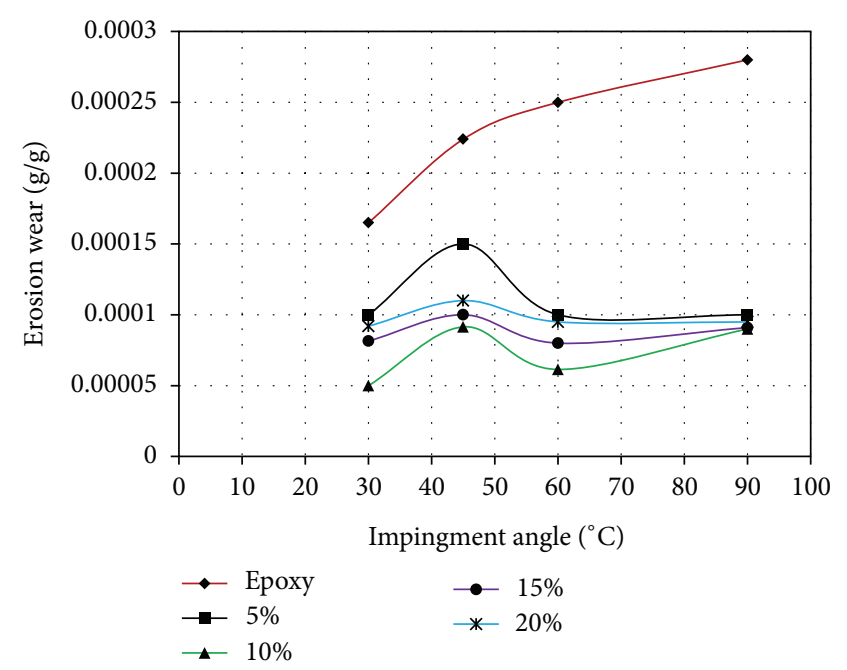

FIgURE 8: Effect of impingement angle on the erosion wear rate of the composites at impact velocity $48 \mathrm{~m} / \mathrm{s}$.

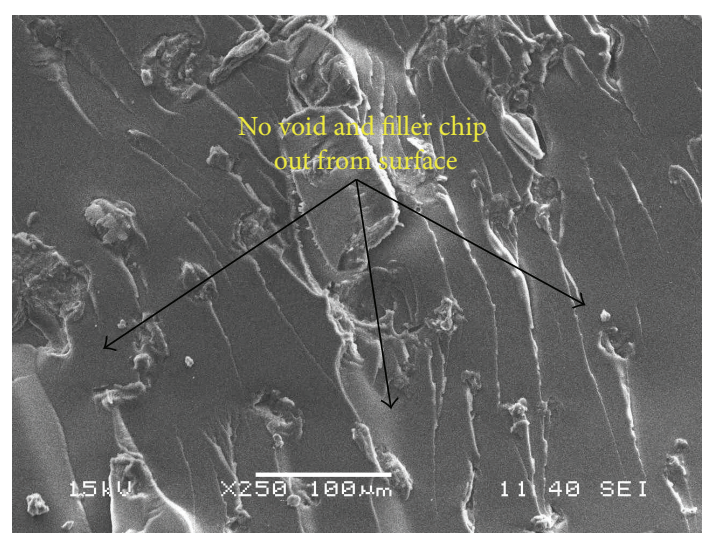

FIGURE 9: SEM of $15 \mathrm{wt} \%$ flexural specimen.

the wood apple shell composite is behaving like semiductile mode of erosion wear [31, 32]. But on further increase in impingement angle from $45^{\circ}$ to $60^{\circ}$, almost all the composites showed minimum erosion rate.

\section{Morphological Characterisation}

The state of dispersion of wood apple particles into the resin matrix plays a significant role on the mechanical properties of the composite. SEM is used to evaluate the particle dispersion in the composite. The morphology of the composites was investigated using a scanning electron microscope (SEM) (JEOL jsm-6480lv) at an accelerating voltage of $15 \mathrm{kV}$ ).

Figure 9 shows the microstructure of $15 \mathrm{wt} \%$ flexural specimen. From the microstructure it is evident that, due to incorporation of $15 \mathrm{wt} \%$ filler with epoxy resin, it is found to have good interfacial bonding between filler and matrix materials. Hence no voids and microcracks were found on the surface of the composite which has given the composite little positive strength to flexural load. But, at $20 \mathrm{wt} \%$, the problem occurred at the time of mixing of filler and resin 


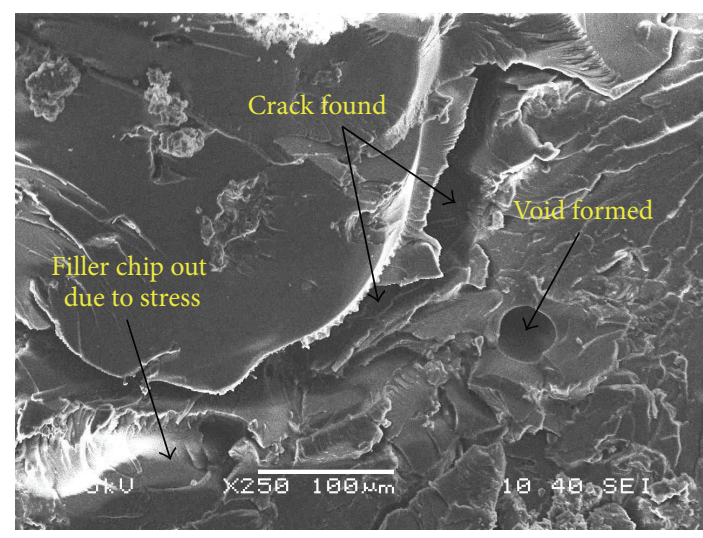

FIGURE 10: SEM of 20 wt $\%$ flexural specimen.

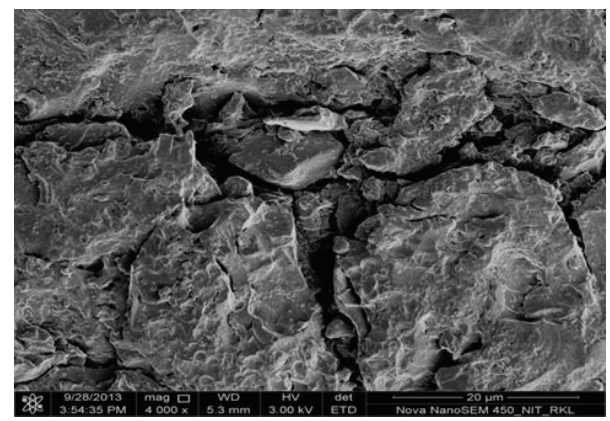

FIGURE 11: SEM of eroded composite surface (impact velocity $48 \mathrm{~m} / \mathrm{s}, 5 \mathrm{wt} \%$ filler, and impact $45^{\circ}$ angle).

due to maximum percentage of reinforcing materials. Due to improper mixing of the fiber and matrix a poor interfacial bonding creates between the material. From Figure 10 it is observed that a small micro cracks and voids are also found on the surface of the composite is also a region for reduction in strength of the composite.

SEM analysis of different composites $(5,10,15$, and $20 \mathrm{wt} \%$ ) with constant impact velocity $48 \mathrm{~m} / \mathrm{s}$ and impingement angle $45^{\circ}$ is shown in Figures 11, 12, 13, and 14. It is observed from Figures 11 and 12 that as the filler percentage increases from 5 to $10 \mathrm{wt} \%$, the cracks formation and material removal on the surface are decreased; this is due to increase of bonding between the filler and the matrix. From Figures 12,13 , and 14 it is clearly noticed that the material removal increases slightly as compared to $10 \mathrm{wt} \%$; this is due to wet ability problem and increase of void fraction content. These morphological analyzed results validate the results obtained in the erosion test.

\section{Conclusions}

(1) Density and void contents of the wood apple shell particulates composites decrease with increasing the filler content as compared to polymer.

(2) With the addition of wood apple shell particles in epoxy resin the tensile and flexural strength increases.

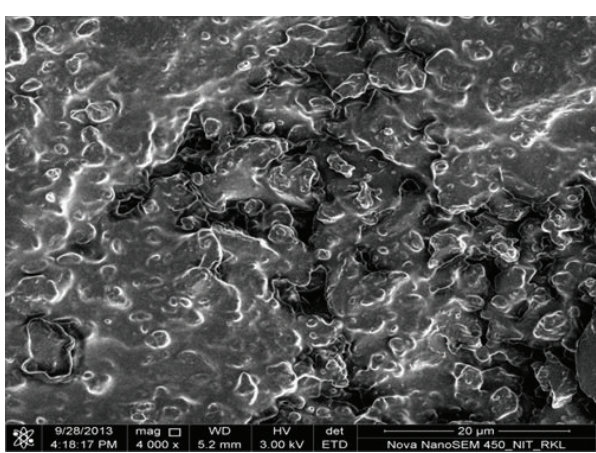

FIGURE 12: SEM of eroded composite surface (impact velocity $48 \mathrm{~m} / \mathrm{s}, 10 \mathrm{wt} \%$ filler, and impact $45^{\circ}$ angle).

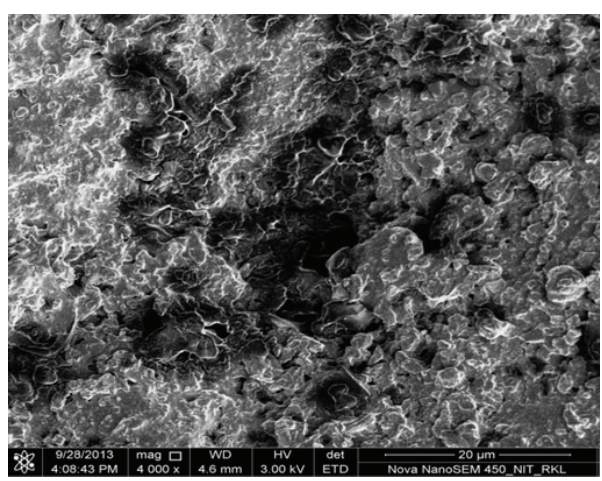

FIGURE 13: SEM of eroded composite surface (impact velocity $48 \mathrm{~m} / \mathrm{s}, 15 \mathrm{wt} \%$ filler, and impact $45^{\circ}$ angle).

However wood apple shell particulates epoxy composite shows better mechanical strength than other polymer.

(3) The increase of the filler plays an important role in improving the ILSS of the mechanical behavior of composites. The improvements of ILSS up to optimum filler content, that is, $15 \mathrm{wt} \%$, indicated better interfacial interaction and effective load transfer between filler and epoxy resin due to better dispersion.

(4) Study of influence of impingement angle on erosion rate of the composites filled with different weight percentages of filler loading reveals their semiductile nature with respect to erosion wear. The peak erosion rate is found to be occurring at $45^{\circ}$ to $60^{\circ}$ impingement angle for all the composite samples under various experimental conditions irrespective of filler loading.

(5) DMA investigations on wood apple shell particles filled composites exhibit the better storage modulus than neat epoxy composite.

(6) From the SEM analysis it is clearly observed that there is a formation of micro cracks, voids, and poor interfacial bonding which causes the reduction in strength these defects can be overcome by employing other fabrication techniques. 


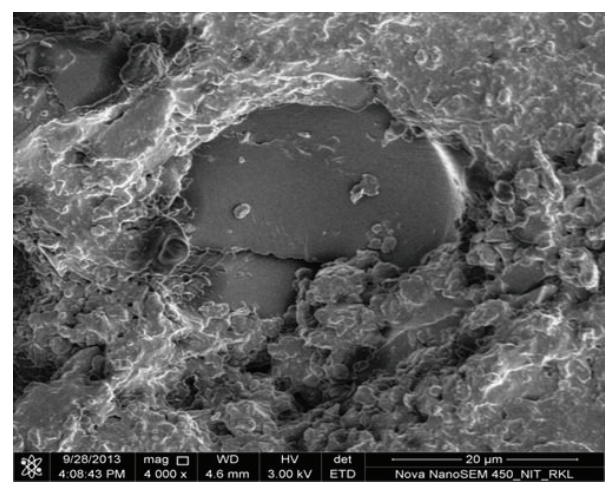

FIGURE 14: SEM of eroded composite surface (impact velocity $48 \mathrm{~m} / \mathrm{s}, 20 \mathrm{wt} \%$ filler, and impact $45^{\circ}$ angle).

\section{Conflict of Interests}

The authors declare that there is no conflict of interests regarding the publication of this paper.

\section{References}

[1] J. Rout, M. Misra, S. S. Tripathy, S. K. Nayak, and A. K. Mohanty, "The influence of fibre treatment of the performance of coirpolyester composites," Composites Science and Technology, vol. 61, no. 9, pp. 1303-1310, 2001.

[2] A. K. Rana, A. Mandal, and S. Bandyopadhyay, "Short jute fiber reinforced polypropylene composites: effect of compatibiliser, impact modifier and fiber loading," Composites Science and Technology, vol. 63, no. 6, pp. 801-806, 2003.

[3] S. V. Joshi, L. T. Drzal, A. K. Mohanty, and S. Arora, "Are natural fiber composites environmentally superior to glass fiber reinforced composites?" Composites A, vol. 35, no. 3, pp. 371376, 2004.

[4] S. K. Nayak, S. Mohanty, and S. K. Samal, "Influence of short bamboo/glass fiber on the thermal, dynamic mechanical and rheological properties of polypropylene hybrid composites," Materials Science and Engineering A, vol. 523, no. 1-2, pp. 32-38, 2009.

[5] H. Pihtili and N. Tosun, "Investigation of the wear behaviour of a glass-fibre-reinforced composite and plain polyester resin," Composites Science and Technology, vol. 62, no. 3, pp. 367-370, 2002.

[6] N. Chand, A. Naik, and S. Neogi, "Three-body abrasive wear of short glass fibre polyester composite," Wear, vol. 242, no. 1-2, pp. 38-46, 2000.

[7] I. Z. Bujang, M. K. Awang, and A. E. Ismail, "Study on the dynamic characteristic of coconut fiber reinforced composites," in Proceedings of the Regional Conference on Engineering Mathematics, Mechanics, Manufacturing and Architechture, Putrajaya, Malaysia, 2007.

[8] H. P. S. Abdul Khalil, S. Hanida, C. W. Kang, and N. A. N. Fuaad, "Agro-hybrid composite: the effects on mechanical and physical properties of oil palm fiber (EFB)/glass hybrid reinforced polyester composites," Journal of Reinforced Plastics \& Composites, vol. 26, no. 2, pp. 203-218, 2007.

[9] S.-Y. Fu, X. Y. Hu, and C.-Y. Yue, "The flexural modulus of misaligned short-fiber-reinforced polymers," Composites Science and Technology, vol. 59, no. 10, pp. 1533-1542, 1999.
[10] R. M. N. Arib, S. M. Sapuan, M. M. H. M. Ahmad, M. T. Paridah, and H. M. D. Khairul Zaman, "Mechanical properties of pineapple leaf fibre reinforced polypropylene composites," Materials \& Design, vol. 27, no. 5, pp. 391-396, 2006.

[11] L. Y. Mwaikambo and E. T. N. Bisanda, "Performance of cottonkapok fabric-polyester composites," Polymer Testing, vol. 18, no. 3, pp. 181-198, 1999.

[12] H. Aireddy and S. C. Mishra, "Tribological behaviour and mechanical properties of bio-waste reinforced polymer matrix composites," Journal of Metallurgy and Materials Science, vol. 53, no. 2, pp. 139-152, 2011.

[13] F. M. Margem, S. N. Monteiro, J. B. Neto, R. J. S. Rodriguez, and B. G. Soares, "The dynamic-mechanical behavior of epoxy matrix composites reinforced with ramie fibers," Revista Matéria, vol. 15, no. 2, pp. 167-175, 2010.

[14] G. Sui, S. Jana, A. Salehi-khojin et al., "Preparation and properties of natural sand particles reinforced epoxy composites," Macromolecular Materials and Engineering, vol. 292, no. 4, pp. 467-473, 2007.

[15] A. Hager, K. Friedrich, Y. A. Dzenis et al., "Studies of erosion wear of advanced polymer composites," in Proceedings of the 10th International Conference on Composite Materials (ICCM '95), K. Street and B. C. Whistler, Eds., pp. 155-162, Wood Head, British Columbia, Canada, 1995.

[16] M. Roy, B. Vishwanathan, and G. Sundararajan, "The solid particle erosion of polymer matrix composites," Wear, vol. 171, no. 1-2, pp. 149-161, 1994.

[17] J. J. Rajesh, J. Bijwe, U. S. Tewari, and B. Venkataraman, "Erosive wear behavior of various polyamides," Wear, vol. 249, no. 8, pp. 702-714, 2001.

[18] G. Anusha, "The removal of iron from wastewater using wood apple shell as adsorbent," in Proceedings of the 2nd International Conference on Environmental Science and Technology (IPCBEE '11), vol. 6, IACSIT Press, Singapore.

[19] R. Ahmad and R. Kumar, "Adsorptive removal of congo red dye from aqueous solution using bael shell carbon," Applied Surface Science, vol. 257, no. 5, pp. 1628-1633, 2010.

[20] K. Begum and M. A. Islam, "Natural fiber as a substitute to synthetic fiber in polymer composites: a review," Research Journal of Engineering Sciences, vol. 2, no. 3, pp. 46-53, 2013.

[21] K. Joseph, S. Varghese, G. Kalaprasad et al., "Influence of interfacial adhesion on the mechanical properties and fracture behaviour of short sisal fibre reinforced polymer composites," European Polymer Journal, vol. 32, no. 10, pp. 1243-1250, 1996.

[22] H. Ismail, M. R. Edyham, and B. Wirjosentono, "Bamboo fibre filled natural rubber composites: the effects of filler loading and bonding agent," Polymer Testing, vol. 21, no. 2, pp. 139-144, 2002.

[23] W. Yao and Z. Li, "Flexural behavior of bamboo-fiber-reinforced mortar laminates," Cement and Concrete Research, vol. 33, no. 1, pp. 15-19, 2003.

[24] S. Kumar and B. Kumar, "Study of mechanical properties of coconut shell particle and coir fibre reinforced epoxy composite," International Journal of Advances in Engineering Research, vol. 4, no. 2, 2012.

[25] S. Ojha, R. Gujjala, S. K. Acharya et al., "Fabrication and study of mechanical properties of orange PEEL reinforced polymer composite," Caspian Journal of Applied Sciences Research, vol. 1, no. 13, pp. 190-194, 2012.

[26] K. K. Basumatary and S. K. Acharya, "Investigation into mechanical properties of Ipomoea carnea reinforced epoxy composite," International Journal of Macromolecular Science, vol. 3, no. 3, pp. 11-15, 2013. 
[27] L. U. Devi, S. S. Bhagawan, and S. Thomas, "Mechanical properties of pineapple leaf fiber-reinforced polyester composites," Journal of Applied Polymer Science, vol. 64, no. 9, pp. 1739-1748, 1997.

[28] M. M. Rahman, S. Zainuddin, M. V. Hosur et al., "Effect of $\mathrm{NH}_{2}$-MWCNTs on crosslink density of epoxy matrix and ILSS properties of e-glass/epoxy composites," Composite Structures, vol. 95, pp. 213-221, 2013.

[29] S. Mohanty, S. K. Verma, and S. K. Nayak, "Dynamic mechanical and thermal properties of MAPE treated jute/HDPE composites," Composites Science and Technology, vol. 66, no. 3-4, pp. 538-547, 2006.

[30] H. Kishi and A. Fujita, "Wood-based epoxy resins and the ramie fiber reinforced composites," Environmental Engineering and Management Journal, vol. 7, no. 5, pp. 517-523, 2008.

[31] J. C. Arnold and I. M. Hutchings, "Erosive wear of rubber by solid particles at normal incidence," Wear, vol. 161, no. 1-2, pp. 213-221, 1993.

[32] J. C. Arnold and I. M. Hutchings, "Model for the erosive wear of rubber at oblique impact angles," Journal of Physics D, vol. 25, no. 1, pp. A222-A229, 1992. 

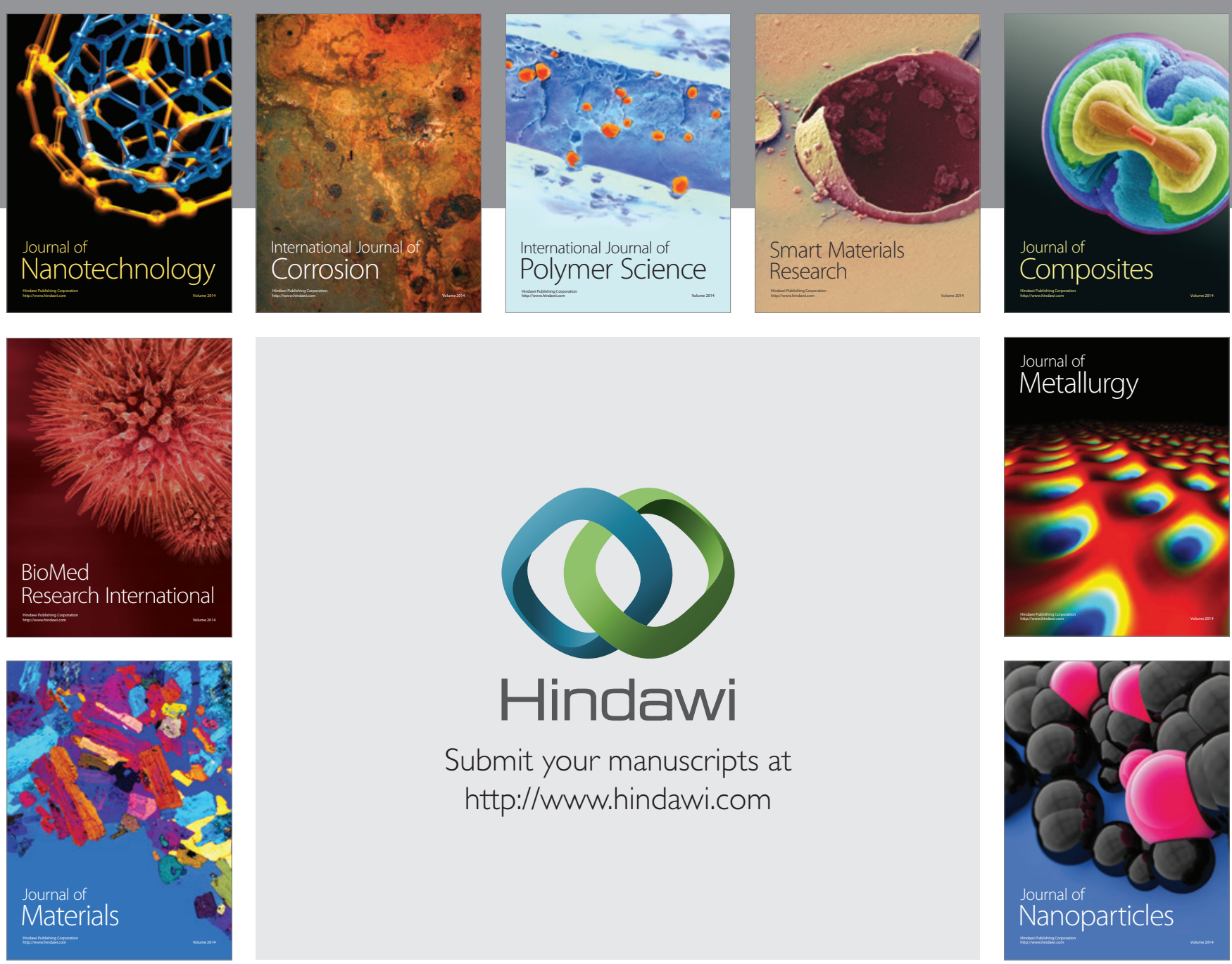

Submit your manuscripts at http://www.hindawi.com
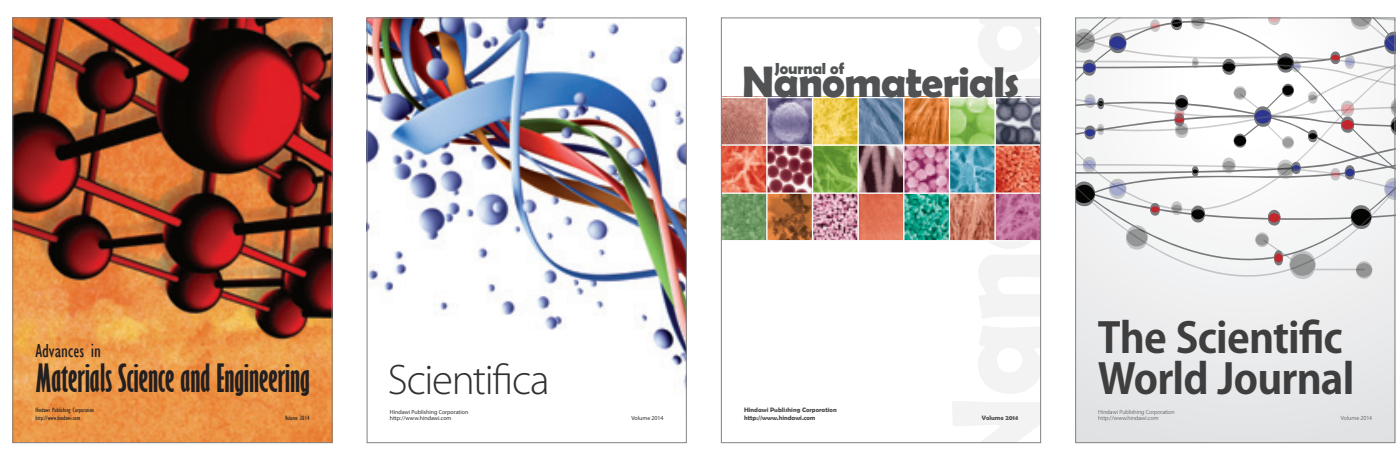

\section{The Scientific World Journal}
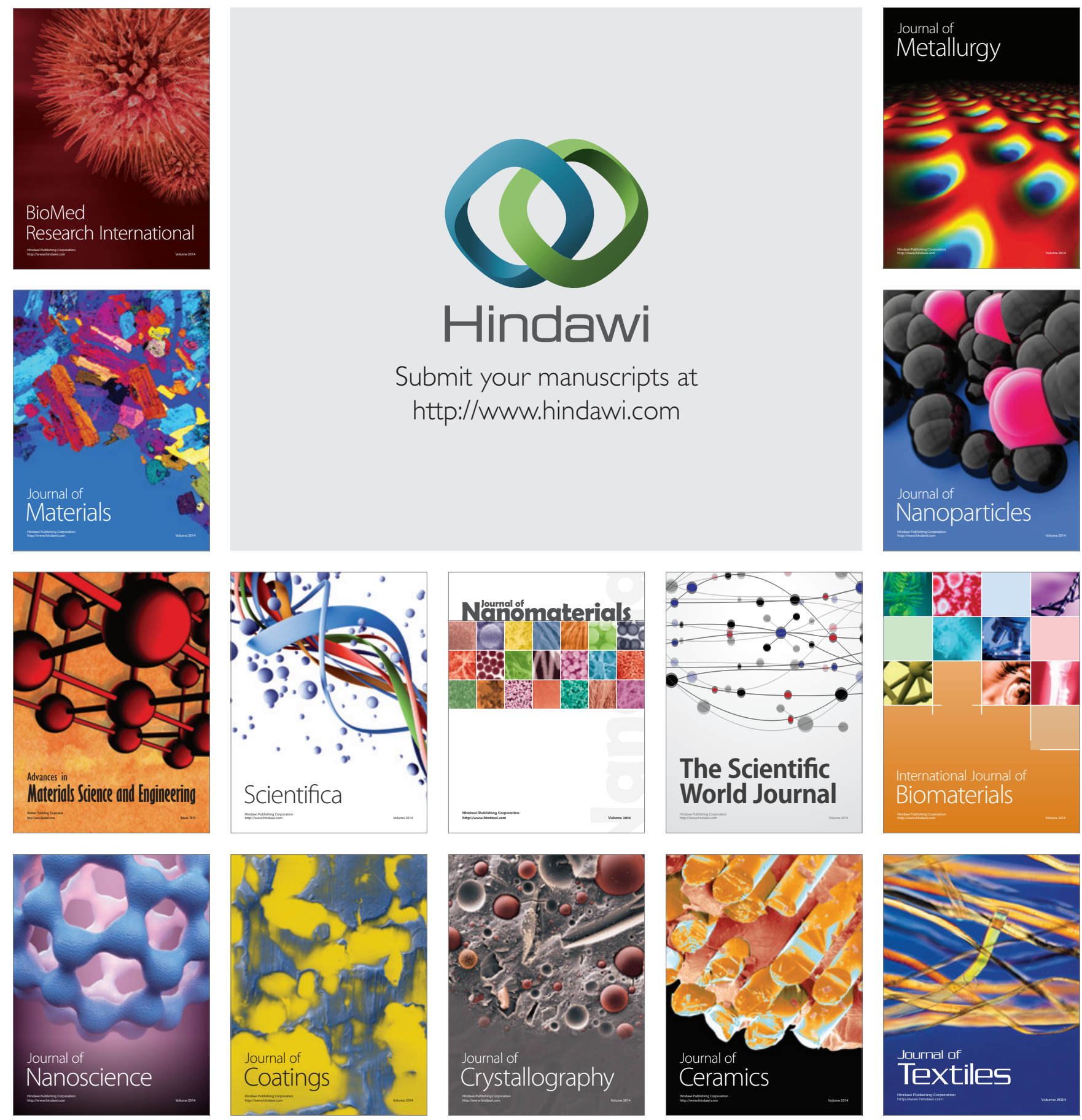